\title{
PENERAPAN METODE KERJA KELOMPOK DENGAN STRATEGI QUESTION STUDENT HAVE UNTUK MENINGKATKAN PRESTASIBELAJAR PPKn SISWA
}

\author{
Ni Wayan Nilawati \\ SMP Negeri 3 Banjarangkan \\ Email: niwayannilawati@gmail
}

\begin{abstract}
ABSTRAK
Penelitian ini dilaksanakan di SMP Negeri 3 Banjarangkan di Kelas VIII Byang prestasi belajar PPKn masih rendah. Tujuan penelitian tindakan kelas ini adalah untuk mengetahui apakah Penerapan Metode Kerja Kelompok Dengan Question Student Have Untuk Meningkatkan Prestasi Belajar PPKn Siswa. Metode pengumpulan atanya adalah tes prestasi belajar. Metode analisis datanya adalah deskriptif. Hasil yang diperoleh dari penelitian ini adalah question student have dengan metode kerja kelompok dapat meningkatkan prestasi belajar PPKnsiswa. Ini terbukti dari hasil yang diperoleh pada awalnya 61,60 setelah diberikan tindakan pada siklus I meningkat menjadi71,80 dan pada siklus II meningkat lagi menjadi 83,20 . Kesimpulan yang diperoleh dari penelitian ini adalah question student have dengan metode kerja kelompok dapat meningkatkan prestasi belajar PPKnsiswa.
\end{abstract}

Kata kunci:metode kerja kelompok, strategi questionstudenthave, prestasibelajar.

\section{ABSTRACT}

This research was carriedoutat SMP Negeri 3 Banjarangkan in Class VIII B where PPKn learning achievement was still low. The purpose of this classaction research is to find out whether the Implementation of Group Work Methods withQuestion StudentHave To Improve Student Learning Performance. The data collectionmethodis a learning achievement test. The data analysis methodis descriptive. The resultsobtainedfromthis study are question students havewith group work methods canimprove student learning achievement PPKn. This is evident from the result sobtainedinitially at 61.60 after being givenaction in the first cycle increased to 71.80 and in thesecondcycleincreasedagainto 83.20. The conclusion obtained from this study is the question student shave with group work method scanimprove student learning achievement PPKn.

Keywords: groupworkmethods, studenthavequestionstrategies, learningachievement

\section{PENDAHULUAN}

Untuk menghadapi tantangan zaman dengan kemajuan teknologi informasi dan ilmu pengetahuan yang serba cepat dibutuhkan guru profesional yang intelektual dan bermoral Pengembangan Profesionalisme Guru (Ali $\&$ Saudagar, 2009). Hal itu sesuai dengan pendapat Giroux, (1988) yang disampaikannya bahwa sosok guru yang mampu memunculkan inovasi dalam pendidikan adalah guru yang menurutnya mau terus berkembang dan belajar seumur hidup, tidak pernah puas dengan apa yang dimengerti, mau membawa perubahan, berpikir kritis, rasional bebas mengembangkan pikiran, reflektif, berani membela kebenaran dan keadilan. Dan tidak dibutuhkan guru yang hanya mempertahankan status quo-nya dan menjalankan tugasnya seperti tukang (Ali \& Saudagar, 2009)

Guru selaku peneliti yang bertugas di SMP Negeri 3 Banjarangkan mencoba melakukan koreksi diri dan refleksi atas hasil belajar awal siswa kelas VIII BSemester ITahun pelajaran2019/2020 yang ditemukan pada saat observasi. Rata- 
JurnalSantiaji Pendidikan, Volume 10, Nomor2, Juli 2020 ISSN 2087-9016, e-ISSN 2685-4694

rata nilai mata pelajaran PPKn siswayang diperoleh

hanyamencapai61,60denganprosentaseketu ntasan belajarsebesar20\%.Nilai tersebut ternyata masih jauh dari Kriteria Ketuntasan Minimal (72,00) yang ditetapkan sekolah.

Pengamatan dan perenungan kembali jalannya proses pembelajaran yang telah dilakukan membuahkan kesimpulan beberapa faktoryang penyebabnya adalah(a) kurang seriusnya guru dalam melakukan persiapan untuk memulai proses pembelajaran; (b) kurangnya daya dukung berupa media/sumber belajar yang dimanfaatkan guru saat pelaksanaan pembelajaran, dan (c) kurangnya daya kreativitas siswa akibat waktu belajar banyak dikuasai guru sehingga ketika usai proses pembelajaran pengetahuan dan pemahaman yang harusnya dikuasai siswa belum tecapai, (d) siswa lebih banyak bermain-main, (e) siswa tidak memahami konsep inti dari materi yang diajar.

Untuk mengatasi masalah tersebut guru selaku peneliti berupaya menerapkan strategi pembelajaran question student have dengan metode kerja kelompok.

Dasar kajian inilah yang kemudian dijadikan landasan guru untuk melakukan pembuktian sendiri dalam proses pembelajaran yang dilakukan, sejauh mana model pembelajaran yang dilaksanakan secara kreatif dengan media pembelajaran yang bertumpu pada kemajuan teknologi informasi dapat meningkatkan prestasi belajar PPKnsiswa. Demikian penulisan yang dapat disampaikan pada latar belakang masalah penelitian ini.

Dengan jelas tertulis arah dari latar belakang masalah maka rumusan penelitian ini dapat disampaikan yaitu: Apakah metode kerja kelompok dengan strategi pembelajaran Question Student have dapat meningkatkan prestasi belajar PPKnsiswakelasVIII BSemester ITahun Pelajaran 2019/2020 SMP Negeri 3 Banjarangkan? Adapun Tujuan dalam penelitian adalah:Untuk meningkatkan prestasi belajar PPKn siswa kelas VIII Bsemester I tahun pelajaran2019/2020 SMP Negeri 3 Banjarangkan setelah menggunakan metode kerja kelompok dengan strategi pembelajaran question student havedalam pembelajaran.

Metode kerja kelompok merupakan salah satu model pembelajaran untuk memupuk kembangkan hasratsosial/kemampuan hidup bermasyarakat karena merupakan modal hidup yang patut dikembangkan. Belajar dengan cara ini berlandaskan konsep dasar bahwa manusia adalah makhluk sosial di sampingindividu.

Metodekerjakelompokataubekerjad alamsituasikelompokmengandungpengerti anbahwasiswadalamsatukelasdipandangse bagaisatukesatuan (kelompok) tersendiriataupundibagiataskelompokkelompokkecil (sub-sub kelompok) (Sudjana, 2010).

(Rianto, 2006) menyampaikan bahwa metode kerja kelompok adalah suatu cara penyajian materi pelajaran yang menitikberatkan interaksi antaranggotakelompokdalammenyelesaika ntugas-tugasbelajarsecarabersama-sama. Metodeinidalampelaksanaannyamempersy aratkanbahwatopikbahasanhendaknyadipili h yang layakuntukkerjakelompok dan dirumuskansecarajelasmengenaituqas-tuqa suntuksetiapkelompok.

Penggunaanmetodebekerjakelompo kdidasarkan pada beberapalatarbelakangsepertikurangnyaala tpelajaranyang tersedia, kemampuansiswa yang 
JurnalSantiaji Pendidikan, Volume 10, Nomor2, Juli 2020 ISSN 2087-9016, e-ISSN 2685-4694

partisipasisiswadalambekerjakelompok,

dan rumitnyamateri yang dipelajari.

Adapunkelebihanmetodeinidapatmemupuk kerjasamaantaranggota,

dapatuntukmegembangkanminatbelajar,

membangunsikapkekeluargaan,

menghindariluapanemosi yang ersifat

individual, dan

melatihsikapkegotongroyongan.

Kelemahannyayaituadanyasifatpribadi

yang inginmenonjolkandirisedangkan yang lemahtergantung pada orang lain, biasanyatugasdidominasiseseorang(Muryat i \& Dewi, 2011)

Istilahkerjakelompokdapatdiartikan sebagaibekerjanyasejumlahsiswa,

baiksebagaianggotakelassecarakeseluruhan atausudahterbagimenjadikelompok-

kelompok yang lebihkecil, untukmencapaisuatutujuantertentusecarabe rsama-sama. Selainitu, kerjakelompok juga ditandai oleh: adanyatugasbersama, pembagiantugasdalamkelompok, dan adanyakerjasamaantaraanggotakelompokd alampenyelesaiantugaskelompok(Yusri, 2011).

Pengertianmetodekerjakelompok

yang

demikianmembawakonsekuensikepadaseti

ap guru yang akanmenggunakannya.

Konsekuensitersebutadalah guru harusbenar-benaryakinbahwatopik yang dibicarakanlayakuntukdigunakandalamkerj akelompok. Tugas yang diberikankepadakelompokhendaknyadiru muskansecarajelas.

Dalampemakaianmetodakerjakelompok, tugas yang diberikandapatsamauntuksetiapkelompok (tugasparalel) atauberbedabedatetapisalingmengisiuntuksetiapkelomp ok (tugaskomplementer).

Berpijak pada pengertiankerjakelompokdiatas, makametodekerjakelompokdapatdiartikans ebagai format belajar-mengajar yang menitikberatkankepadainteraksiantaraangg ota yang satudengananggota yang lain dalamsuatukelompokgunamenyelesaikantu gas-tugasbelajarsecarabersama-sama.

Dijabarkanbahwa proses kelompokmemilikikarakteristikatausegisegirelasi, interaksi, partisipasi, kontribusi, afeksi, dan dinamika. Tiapindividuberhubungansatusama lain; tiapindividumemberikansumbanganpikiran ; tiapindividusalingmempengaruhi; tiapindividuikutaktif;

tiapindividumendapatpembagiantugas; dan tiapindividumengembangkansifat-sifat

personal-sosial-moral, dan karenanyakelompoksenantiasahidupberuba h, berkembang, yang berartibersifatdinamis(Hamalik, 2005). Agar

kerjakelompokmenjadilebihefektif dan semuaanggotakelompokterlibataktif, setiapanggotakelompokdiberitugassebagail eader, reader,summarizer,reporter, and observer.Leaderbertugasuntuk(1)

memulaikegiatan;(2)memastikansemuaang gotaberpartisipasi;(3)memastikansemuaan ggotatetapterfokus pada fokusmasalah (4) menjagadiskusikelompoktetapberlansunga ktif;dan(5)

mengaturwaktu.Perananreaderadalah (1)membacadengannyaringsemuateksmau puninstruksi;(2)membacapertanyaan;dan(3 )

Peranansummarizeradalah:(1)

menjelaskansituasiataumasalahdengan

kata-katasendiritanpamembaca;

memastikansemuaanggotamemahamimasa lahdansituasi.

Perananobserveradalahmengamatisemuaan ggotakelompokdan

(2)bilaperlumembuatcatatanobservasi.Dan dalamsemuaaktifitassemuaanggotaharus 
JurnalSantiaji Pendidikan, Volume 10, Nomor2, Juli 2020 ISSN 2087-9016, e-ISSN 2685-4694

(1) mengemukakanpendapat; menjelaskanpendapatdengancontoh dan alasan; (3) salingbertanyatentang ideanggotakelompoklainnya(Hadriana,

2009)

\section{Salah}

satucarauntukmeningkatkanminat dan hasilbelajarsiswayaitudenganstrategipemb elajaran yang bervariasi.Salah satustrategi yang digunakanadalahQuestion Student Haveyaitucarayang

mudahuntukmempelajarisebuahteknikuntuk mendapatkanpartisipasimelaluitulisandaripa dapercakapan. Seperti yang dikemukakan oleh Hisyamzaini (2004) yang dikutifdari(Sumaryati, 2009)), bahwastrategiQuestions Students Haveadalahpembelajaran yang menekankan pada siswauntukaktifdan menyatukanpendapat dan mengukursejauh mana

siswamemahamipelajaranmelaluipertanyaan tertulis.

\section{StrategiQuestions}

\section{Students}

Havemerupakan salah satustrategimengajar yang dikembangkan oleh Mel Silberman, seorang yang memangberkompetendalampsikologipendi dikan.Strategiinimerupakansekumpulandar i 101 strategipengajaran.Sebuahmetode yang menitikberatkan pada kemampuansiswauntukmengembangkanpo tensi yang adadalamdirinya, karenastrategiinimerupakancara yang tidakmembuatsiswatakutuntukmempelajari apa yang merekabutuhkan dan harapkan. Strategiinimemanfaatkanteknik yang mengundangpertisipasimelaluipenulisan, bukanpembicaraan(Silberman, 2002).

$$
\text { Peran }
$$

guru bukanhanyamemberikaninformasimelaink an juga menggerakkan dan memberifasilitasbelajar agar proses belajarlebihmemadai. satunyaadalahdenganpenerapanstrategipe mbelajaranQuestions Student Have (QSH).Untukmengajaksiswaberperanaktif danbertanggungjawabdalammelaksanakan kegiatanpembelajaran.Questions Student Have (QSH)merupakan salah satustrategipembelajaran yang menekankan pada siswauntukaktif dan menyatukanpendapat dan mengukursejauh mana

siswamemahamipelajaranmelaluipertanyaa ntertulis(Yusuf, 2012).

\section{Strategiquestion}

student havedikembangkanuntukmelatihpesertadid ik agar memilikikemampuan dan ketrampilanbertanya.

Pembelajarandenganmetodeinidiawalideng anmembagikelasmenjadi

4
kelompok.Jumlahkelompoksebaiknyadises uaikandenganjumlahpesertadidik. Setiapkel ompokmelaporkansecaratertulispertanyaan yangtelahmenjadimilikkelompok (mewakilikelompok).

Guru melakukanpemeriksaanterhadappertanyaan daritiap-tiapkelompok, mungkinadapertanyaanyang substansinyasama. Pertanyaanpertanyaanyangsudahdiseleksi oleh guru dikembalikankepadapesertadidikuntukdija wabsecaramandirimaupunkelompok.Jawab anlisanmaupuntulisan(Suprijono, 2009)

$$
\text { Langkah- }
$$

langkahpelaksanaanteknikQuestion

Student Have, menurutMilati (2011: 1819) adalah: 1) Bagikanpotonganpotongankertas (ukurankartu pos) kepadasiswa; 2) Minta setiapsiswauntukmenuliskanpertanyaanapa saja yang berkaitandenganmateripelajaran; 3) Setelah semuaselesaimembuatpertanyaanmasingmasingdimintauntukmemberikankertas yang berisipertanyaankepadakelompokdi sampingkirinyadalamhaliniposisi duduk 
JurnalSantiaji Pendidikan, Volume 10, Nomor2, Juli 2020 ISSN 2087-9016, e-ISSN 2685-4694

siswaadalahlingkaran,

nantinyaakanterjadigerakanperputarankert

assearahjarum jam; 4) Pada

saatmenerimakertasdarikelompoklainsiswa

dimintauntukmembacapertanyaan yang

ada.Jikapertanyaanituingidiketahuijawaban

nya, makadiaharusmemberitandaceklis, jikatidakingindiketahuiatautidamenarik,

berikanlangsung pada kelompok di sampingkiri. Dan begituseterusnyasampaisemuasoalkembali kepadapemiliknya.

Ketikakertaspertanyaantadikembalikepada pemiliknya,

siswadimintauntukmenghitungtandaceklis

$(\sqrt{ })$ yang ada pada kertasnya. Pada saatinicarilahpertanyaan yang mendapatceklis paling banyak; 6) Berilahresponkepadapertanyaan-

pertanyaantersebutdengan:

jawabanlangsungsecarasingkat dan (b) menundajawabandaripertanyaantersebutsa mpaiwaktu yang tepatatauwaktumembahastopiktersebut; 7) Jikacukupwaktu,

mintabeberapasiswauntukmembcakanperta nyaan yang iatulismeskipuntidakmendapattandaceklis yang banyakkemudianberikanjawaban; dan 8) Guru melakukanpemeriksaanterhadappertanyaan daritiap-tiapkelompok,

mungkinadapertanyaan yang substansinyasama.

Teknik ini juga dapatdilakukandenganmemintasiswauntuk menjawabsemuapertanyaan yang diajukan oleh kelompoktersebut, sehinggafaseiniakandapatmengidentiikasip ertanyaan mana yang mendapatjawabanterbanyak, sebagaiindikasipenguasaananakterhadapob jek yang dipertanyakan.
Pembahasanmengenaiistilahprestas ibelajardalam dunia pendidikanmerupakansesuatuhal yang sangatmenarik.Halitudikarenakankeberada anistilahtersebutsangatbermnfaatbagiberba gaipihak yang terlibatterutamapendidik, pesertadidik, orang tua dan sekolah.Prestasibelajar yang telahdiperolehdaripelaksanaanevaluasidap atdijadikantolokukurtentangsejauh mana keberhasilankegiatanpembelajaran yang sudahdilakukanterhadappesertadidiknya.

Prestasibelajarmerupakandapatdiop erasionalkandalambentukindikatorindikatorberupanilairaport, indeksprestasistudi, angkakelulusan dan predikatkeberhasilan(Azwar, 1996).

Dalambukupsikologikependidikanm endefinisikanprestasiatauhasilbelajarpesert adidikadalah: dayaataukemampuanseseoranguntukberfik ir dan berlatihketikamengerjakantugasataukegiat antertentu dan kegiatanpembelajaran di sekolah;

prestasibelajartersebutterutamadinilaiaspek kognitifnya (transferable) karena yang bersangkutandengankemampuanpesertadid ikdalampengetahuanatauingatan, pemahaman, aplikasi, analisis, sintesa, dan evaluasi; prestasibelajarpesertadidikdibuktikan dan ditunjukkanmelaluinilaiatauangkanilaidari hasilevaluasi yang dilakukan oleh guru terhadaptugaspesertadidik dan ulanganulanganatauujian yang ditempuhnya(Abin, 2000).

SedangkanMenurutRachmanNatawi djayadikemukakanbahwa:

"Apabilasiswamenguasaimateripelajaran

di atas 75\%

dapatdikatakanprestasibelajarPPKnsiswati nggi.

Apabilapenguasaanmaterisiswamencapai 
JurnalSantiaji Pendidikan, Volume 10, Nomor2, Juli 2020 ISSN 2087-9016, e-ISSN 2685-4694

$60 \%-75 \%$ menunjukkan pada

prestasibelajar yang sedang, dan apabilapenguasaanmaterisiswa di bawah $50 \%$ menunjukkanprestasibelajar yang rendah(Depdiknas, 2005).

Jadipengertianbahwaprestasibelajarituident ikdenganpenggunaanmateripelajaran.Kare nahakikatdarinilaiperolehanbelajardiawali darikemampuansiswauntukmenjawabsoalsoal yang diajukan guru secaratertulis. Dengandemikiantingkatpenguasaanmateri masing-masingsiswa,

secaraotomatisakanmembedakanprestasibe lajarnya.

PrestasiBelajaradalahsuatuperubaha nperilaku,

akibatinteraksiberbagaikomponen.Interaksi dilakukansecarasengaja, sistematis, danterencana.Dengandemikianbelajardikat akanberhasilapabilaterjadiperubahandalam diriindividu.Dari

uraiantersebutmakaprestasibelajaradalahse suatu yang dicapaiataudiperolehsiswaberkatadanyausa haataufikiran yang mana haltersebutdinyatakandalambentukpengusa an, pengetahuan dan kecakapan yang terdapatdalamberbagaiaspekkehidupan, sehingganampak pada diriindividuperubahantingkahlakusecarape rmanen.Ciri-

ciribelajaradalahperubahansecarasadar yang

meliputiseluruhaspektingkahlakukearah yang lebihbaik, belajarsebagaihasildarilatihan dan pengalamansertaperubahan yang terjadirelatifmenetap.

\section{METODE PENELITIAN}

Penelitian tindakan kelas berlokasi di SMP Negeri 3 Banjarangkan, yang terletak di DesaNyalianKecamatanBanjarangkan di
KabupatenKlungkung.Subjekyang menjadi sumber informasi dalam penelitian iniadalahsemuasiswakelasVIII B SMP Negeri 3 BanjarangkanSemester Itahunpelajaran2019/2020

yangberjumlah30 orang siswa, 16 orang siswalaki-laki dan 14 orang siswaperempuan.

PeningkatanprestasibelajarPPKnsiswatentu sajatidakbisadiabaikan. Oleh karenanyafokusdalampenentuanobjekpenel itiantertuju pada peningkatanprestasibelajartersebut.Pelaksa naan

di

kelasmengikutialurrancanganpenelitian yang disampaikan oleh Model Spiral PenelitianTindakan Kelas (Hopkins, 1993), dalam(Arikunto, Suharsimi: Supardi, 2006)Sumber data dari penelitian ini adalah siswa kelas VIII B, dan untuk mendapatkan informasi tentang tingkat keberhasilan mereka setelah diberikan tindakan, guru selaku peneliti mengadakanevaluasidengan menggunakan tes essay untukmengukurprestasi belajar PPKnsiswa. Analisis data merupakan salah satu proses penelitian yang dilakukan setelah guru selaku peneliti berhasil mengumpulkan semua data yang diperlukan secara lengkap guna memecahkan permasalahan yang diteliti. Untuk penelitian ini, analisis dilakukan secara deskriptif kuantitatif sehubungan data yang diperoleh peneliti berbentuk angka. Analisis kuantitatif dilakukan secara statistik sederhana dengan melakukan penyajian data, menghitung mean, median, modus, serta melakukan penggambaran secara rinci dalam bentuk tabel dan grafik. Data yang diperoleh kemudian dideskripsikan untuk mendapatkan gambaran hasil penelitian yang

diinginkan.Pelaksanaanpenelitianuntukme 
JurnalSantiaji Pendidikan, Volume 10, Nomor2, Juli 2020 ISSN 2087-9016, e-ISSN 2685-4694

nyelesaikantindakandariperencaaan,

pelaksanaan, observasi, dan refleksiakandilakukansesuaibataswaktu yang ditentukan.

Dalampenelitianinijadwalpelaksanaantinda kanakandilakukandaribulanJuli2019sampa iNopember2019.

\section{HASIL PENELITIAN DAN PEMBAHASAN}

Padakegiatanawalnilairata-

ratahanyamencapai61,60denganhanya 7 orang $(23,33 \%)$ yangmemperolehnilai di atas KKM, 4 orang $(13,33 \%)$ memperolehnilaisamadenganKKM dan19 orang $(63,33 \%)$ memperolehnilai di bawah KKM.

Data tersebutmenunjukkanrendahnyaprestasibel ajarPPKnsiswakelas VIII Bsemester Itahunpelajaran2019/2020 SMP Negeri3 Banjarangkanpadaawalnya.Hasilpenelitian padasiklus dapatdiuraiakansebagaiberikut:

1. Rata-rata (mean)

Menghitung

rata-rata

kelasdilakukandengancara: $\frac{\text { Jumla hnilai }}{\text { Jumla hsiswa }}$

$=\frac{2.154}{30}=71,80$

2. Median (titiktengahnya)

Untuk median yang diperolehdari data siklus

denganmenggunakancaratersebutadala h: 73,50

3. Modus

Angka yang paling
banyakmunculdalam data yang
sudahdihasilkanmerupakan modus dari
data tersebut. Angkatersebutadalah:
72,00

$$
\begin{aligned}
\text { Banyak kelas }(\mathrm{K}) & =1+3,3 \times \log (\mathrm{N}) \\
& =1+3,3 \times \log 30 \\
& =1+3,3 \times 1,48 \\
& =1+4,88=5,88 \rightarrow 6
\end{aligned}
$$

Rentangkelas $(\mathrm{r})=$ skormaks-skor min $=85-50=35$

\begin{tabular}{|c|c|c|c|c|}
\hline $\begin{array}{l}\text { No } \\
\text { Urut }\end{array}$ & Interval & $\begin{array}{c}\text { Nilai } \\
\text { Tengah }\end{array}$ & $\begin{array}{c}\text { Frekuensi } \\
\text { Absolut }\end{array}$ & $\begin{array}{c}\text { Frekuensi } \\
\text { Relatif }\end{array}$ \\
\hline 1 & $50-55$ & 52,50 & 4 & 13,33 \\
\hline 2 & $56-61$ & 58,50 & 0 & 0,00 \\
\hline 3 & $62-67$ & 64,50 & 4 & 13,33 \\
\hline 4 & $68-73$ & 70,50 & 7 & 23,33 \\
\hline 5 & $74-79$ & 76,50 & 7 & 23,33 \\
\hline 6 & $80-85$ & 82,50 & 8 & 26,67 \\
\hline & Total & & 30 & 100 \\
\hline
\end{tabular}

Panjang kelas interval (i) $=\frac{r}{K}=\frac{35}{6}=$ 5,83

Tabel1. Data Kelas Interval Siklus I

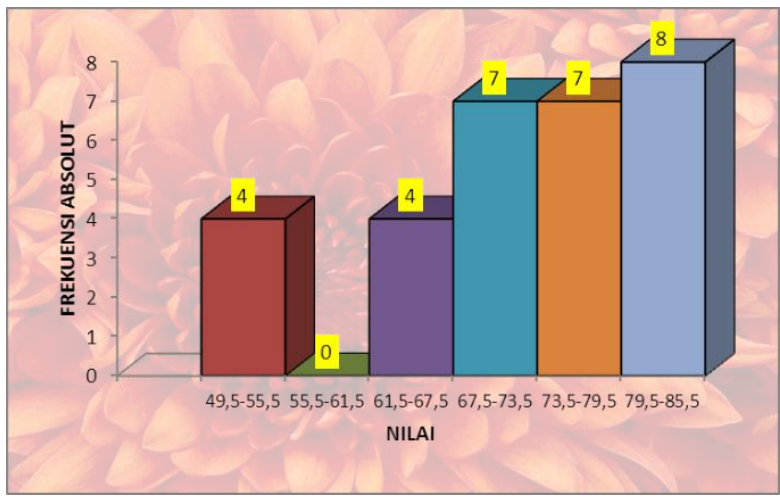

Gambar 1. Histogram Siklus I

Pada

siklus

II penelitimencobamemaparkanhaltersebutde nganlengkap pada bagianini yang dilakukanadalah:

1. Rata-rata (mean) : 83,20

2. Median (titiktengahnya) $: 85,00$

3. Modus : 88,00

Banyak kelas $(\mathrm{K})=1+3,3 \times \log (\mathrm{N})$

$=1+3,3 \times \log 30$

$=1+3,3 \times 1,48$

$=1+4,88=5,88$

Rentangkelas (r) = skormaks-skor min

$$
=85-50=35
$$

Panjang kelas interval (i) $=\frac{r}{K}=\frac{35}{6}=5,83$

Tabel2. Data Kelas Interval SiklusII

No Interval Nilai Frekuensi Frekuensi


JurnalSantiaji Pendidikan, Volume 10, Nomor2, Juli 2020 ISSN 2087-9016, e-ISSN 2685-4694

\begin{tabular}{|c|c|c|c|c|}
\hline Urut & & Tengah & Absolut & Relatif \\
\hline 1 & $70-74$ & 72 & 5 & 16,67 \\
\hline 2 & $75-79$ & 77 & 3 & 10,00 \\
\hline 3 & $80-84$ & 82 & 4 & 13,33 \\
\hline 4 & $85-89$ & 87 & 13 & 43,33 \\
\hline 5 & $90-94$ & 92 & 2 & 6,67 \\
\hline 6 & $95-99$ & 97 & 3 & 10,00 \\
\hline & Total & & 30 & 100 \\
\hline
\end{tabular}

adidikmerasamampumenguasaimateriyang diajarkan.

Berdasarkansemuahasilyangdiperol eh, dapatdisampaikan saran sebagaiberikut :

Dalammelaksanakanpembelajaranstrategi pembelajaran questionstudenthave dengan metode kerja kelompokdiperlukan persiapan yangmatang. Olehkarenanyadisarankan agar gurugurumampumenentukanataumemilihtopiky angbenar-

benarbisaditerapkandalampemnbelajarany angmenggunakanstrategi pembelajaran questionstudenthave dengan metode kerja kelompok.

Untukdapatmeningkatkanhasilbelajarsiswa

\section{Gambar 2.Histogram Siklus II}

\section{SIMPULAN DAN SARAN}

Pembelajaranyangdilaksanakanden ganmenggunakanstrategi pembelajaran questionstudenthave dengan metode kerja kelompok

memilikidampakpositifdalammeningkatka nhasilbelajarsiswa di SMP Negeri 3 Banjarangkanyangditandaidenganpeningka tanketuntasanbelajarsiswadalamsetiapsiklu s, yaitu: 61,60padasiklus I menjadi71,80danpadasiklus II menjadi83,20.

Haliniberartipembelajaranmenggunakanm etode kerja kelompokdenganstrategi questionstudenthavepada matapelajaranPPKnmempunyaipengaruhp ositif, yaitudapatmeningkatkanprestasibelajarPP Knsiswa.

Dari data di atasdapatdisimpulkan, penerapanmetode kerja kelompokdenganstrategi pembelajaran questionstudenthave efektifuntukmeningkat kankegiatanbelajarmengajarsehinggapesert

guru hendaknyalebihseringmelatihsiswadengan kegiatanpenemuan,

walaudalamtarafyangsederhana, di mana siswanantinyadapatmenemukanpengetahua nbaru,

memperolehkonsepdanketerampilan, sehinggasiswaberhasilataumampumemeca hkanmasalah-masalahyangdihadapinya. 3) Perluadanyapenelitianyanglebihlanjut, karenahasilpenelitianinihanyadilakukan di SMP Negeri 3 Banjarangkanpadasemester Itahunpelajaran2019/2020.

\section{DAFTAR PUSTAKA}

Abin, S. (2000). Psikologi Kependidikan. Bandung: PT Remaja Rosdakarya.

Ali, I., \& Saudagar, F. (2009). Pengembangan Profesionalisme Guru.

Arikunto, Suharsimi: Supardi, S. (2006). Penelitian Tindakan Kelas.

Azwar, S. (1996). Pengantar Psikologi Intelegensi. Jogyakarta: Pustaka Pelajar.

Depdiknas. (2005). Peraturan Pemerintah Republik Indonesia Nomor 19 Tahun 
JurnalSantiaji Pendidikan, Volume 10, Nomor2, Juli 2020 ISSN 2087-9016, e-ISSN 2685-4694

2005 Tentang Standar Nasional Pendidikan.

Hadriana. (2009). Meningkatkan Kemampuan Menulis Mahasiswa Semester III Program Studi didikan Bahasa Inggris FKIP Unri Melalui Metode Group Project. Jurnal Bahasa, Volume 4(8).

Hamalik, O. (2005). Kurikulum dan Pembelajaran. Jakarta: PT. Bumi Aksara.

https://idiscover.lib.cam.ac.uk/primoexplore/search?query=any,contains, $M$ cKay, P. (2006). Assessing Young Language Learners. Cambridge: Cambridge University Press.\&tab=cam_lib_coll\&search_sc ope $=$ SCOP_CAM_ALL\&vid $=44 \mathrm{CA}$ M_PROD\&offset $=0$

Muryati, S., \& Dewi, K. (2011). Strategi Pembelajaran Bahasa Indonesia. Univet Bantara Press. Sukoharjo.

Rianto, M. (2006). Pendekatan, Strategi, dan Metode Pembelajaran. Bahan Ajar Diklat Mata Pelajaran Pendidikan Kewarganegaraan SMA Jenjang Dasar. Direktorat Jenderal Peningkatan Mutu Pendidik Dan Tenaga Kependidikan. Departemen Pendidikan Nasional. Pusat Pengembangan Penatar. Malang. https://doi.org/10.5005/jp/books/1140 $1 \_16$

Silberman, M. L. (2002). Active Learning: 101 Strategi Pembelajaran Aktif. Yogyakarta : Yaipenda.

Sudjana, N. (2010). Dasar-Dasar Proses Belajar Mengajar. Penerbit: Sinar Baru Algensindo. Bandung.

Sumaryati. (2009). Prestasi Belajar dalam Pengajaran Remedial pada Mata Pelajaran IPS Ekonomi Kelas II Semester 1 SLTP Negeri 1 Linggang Bingung Kabupaten Kutai Barat.

Suprijono, A. (2009). Cooperative Learning Teori dan Aplikasi PAIKEM. Penerbit: Pustaka Belajar. Yogyakarta.

Yusri, M. (2011). Makalah Metode Pembelajaran. Http://Yusri
Keren85.Blogspot.Co.Id/2011/.

Yusuf. (2012). Penerapan Strategi Pembelajaran Question Student Have (QSH) Untuk Meningkatkan Motivasi Dan Hasil Belajar Biologi Siswa Kelas VIII3 SMP Negeri I Rimba Melintang Tahun Pelajaran 2011/2012. Jurnal Biogenesis, 82. 